\title{
On the Nature of Prejudice: Automatic and Controlled Processes
}

\author{
John F. Dovidio \\ Colgate University \\ Kerry Kawakami \\ University of Nijmegen, The Netherlands \\ Craig Johnson \\ Hofstra University \\ Brenda Johnson \\ Colgate University \\ and \\ Adaiah Howard \\ Colgate University
}

Received: June 12, 1996; revised: January 10, 1997; accepted: January 23, 1997

The present research, involving three experiments, examined the existence of implicit attitudes of Whites toward Blacks, investigated the relationship between explicit measures of racial prejudice and implicit measures of racial attitudes, and explored the relationship of explicit and implicit attitudes to race-related responses and behavior. Experiment 1, which used a priming technique, demonstrated implicit negative racial attitudes (i.e.,

The research reported in this article was supported by NIMH Grant MH 48721 . We are grateful for the helpful comments and suggestions offered by Mahzarin Banaji, Clark McCauley, and two anonymous reviewers.

Address correspondence and reprint requests to John F. Dovidio, Department of Psychology, Colgate University, Hamilton, NY 13346. E-mail: JDOVIDIO@CENTER.COLGATE.EDU. 
evaluative associations) among Whites that were largely disassociated from explicit, self-reported racial prejudice. Experiment 2 replicated the priming results of Experiment 1 and demonstrated, as hypothesized, that explicit measures predicted deliberative racerelated responses (juridic decisions), whereas the implicit measure predicted spontaneous responses (racially primed word completions). Experiment 3 extended these findings to interracial interactions. Self-reported (explicit) racial attitudes primarily predicted the relative evaluations of Black and White interaction partners, whereas the response latency measure of implicit attitude primarily predicted differences in nonverbal behaviors (blinking and visual contact). The relation between these findings and general frameworks of contemporary racial attitudes is considered. ๑ 1997 Academic Press

The distinction between explicit and implicit memory processes has recently received substantial empirical attention (e.g., Loftus \& Klinger, 1992; Schacter, 1990; Wegner \& Bargh, 1997). Similarly, Greenwald and Banaji (1995; Banaji \& Greenwald, 1994) have emphasized the importance of distinguishing between explicit and implicit indices of attitudes. Explicit measures of attitudes operate in a conscious mode and are exemplified by traditional self-report measures. Implicit attitudes, in contrast, operate in an unconscious fashion and represent "introspectively unidentified (or inaccurately identified) traces of past experience that mediate favorable or unfavorable feeling, thought, or action toward social objects" (Greenwald \& Banaji, 1995, p. 8). The present research, involving three experiments, examined the existence of implicit racial attitudes of Whites toward Blacks, investigated the relationship between explicit measures of racial prejudice and implicit measures of attitudes, and explored the relationship of explicit and implicit attitudes to race-related responses and behaviors.

Although intuitively one might expect that unconscious activation of general associations or attitudes, as assessed in response latency paradigms, and selfreported prejudice may be rooted in the same experiences and socialization history and thus be directly related, research typically does not support this expectation (Banaji \& Greenwald, 1995; Devine, 1989; Fazio, Jackson, Dunton, \& Williams, 1995; Gaertner \& McLaughlin, 1983). Theoretically, response latency measures and self-report measures may reflect the distinction between activation and application identified by Gilbert and Hixon (1991). The presentation of an attitude object may automatically activate an associated evaluation from memory (Fazio et al., 1995) which may influence subsequent judgments. However, as Gilbert and Hixon (1991) argue, automatic activation "does not mandate such use, nor does it determine the precise nature of its use. It is possible for activated information to exert no effect on subsequent judgments or to have a variety of different effects" (p. 512). Thus, it is quite possible that response latency measures of activation and self-report prejudice measures could be empirically unrelated.

A dissociation between response latency measures of implicit attitudes and self-reported attitudes may be likely to be observed for socially sensitive issues (Dovidio \& Fazio, 1992) and particularly for racial attitudes. Devine (1989), for example, proposed that high- and low-prejudiced people are equally knowledgeable about cultural stereotypes about minority groups and similarly activate these 
stereotypes automatically with the real or symbolic presence of a member of that group. Low- and high-prejudiced individuals differ, however, in their personal beliefs and their motivations to control the potential effects of the automatically activated cultural stereotypes. Lower prejudiced people are more motivated to control, suppress, and counteract their initial, automatic, biased reactions. Thus unconscious associations, which are culturally shared and automatically activated, may be disassociated from expressions of personal beliefs that are expressed on self-report measures of prejudice and systematically vary.

A dissociation between automatic responses and self-reported prejudice is also consistent with other conceptions of the current nature of racial prejudice among Whites, such as the aversive racism and the symbolic (or modern) racism framework. These frameworks suggest that, whereas traditional forms of prejudice are direct and overt, contemporary forms are indirect and subtle. Aversive racism (see Dovidio \& Gaertner, 1991, 1997; Dovidio, Mann, \& Gaertner, 1989; Gaertner \& Dovidio, 1986; Kovel, 1970) has been identified as a modern form of prejudice that characterizes the racial attitudes of many Whites who endorse egalitarian values, who regard themselves as nonprejudiced, but who discriminate in subtle, rationalizable ways. According to the aversive racism perspective, many Whites who consciously and sincerely support egalitarian principles and believe themselves to be nonprejudiced also unconsciously harbor negative feelings and beliefs about Blacks, which may be based in part on almost unavoidable cognitive, motivational, and sociocultural processes (see Gaertner \& Dovidio, 1986). These unconscious negative feelings and beliefs may be implicit attitudes, whereas the conscious, self-reported egalitarian attitudes of aversive racists may represent explicit attitudes.

According to symbolic racism theory (Sears, 1988) and its related variant modern racism theory (McConahay, 1986), negative feelings toward Blacks that Whites acquire early in life persist into adulthood but are expressed indirectly and symbolically, in terms of opposition to busing or resistance to preferential treatment, rather than directly or overtly, as in support for segregation. McConahay (1986) further proposes that because modern racism involves the rejection of traditional racist beliefs and the displacement of anti-Black feelings onto more abstract social and political issues, modern racists, like aversive racists, are relatively unaware of their racist feelings. This conception of prejudice, like the aversive racism framework, would also suggest a potential dissociation between explicit and implicit racial attitudes.

The first experiment in the present set of studies used a priming procedure to assess the implicit racial attitudes of Whites. The relationship between this implicit measure of attitudes and explicit, self-report measures of racial bias was also explored. The second experiment also assessed implicit and explicit racial attitudes but, in addition, investigated how well these measures predicted deliberative judgments (of the guilt of a Black defendant) and spontaneous reactions (in a word-completion task). The third experiment tested the relative predictive validity of implicit and explicit measures of racial attitudes on relatively deliberative 
ratings of Blacks and Whites and relatively spontaneous nonverbal behaviors during actual interracial interaction.

\section{EXPERIMENT 1}

This experiment was designed to assess the implicit attitudes of Whites about Blacks and Whites. Previous research has demonstrated relationships between racial category primes and evaluations in response latency paradigms (e.g., Dovidio, Evans, \& Tyler, 1986), but the research did not necessarily demonstrate automatic processes (Bargh, 1994; Greenwald \& Banaji, 1995). Participants were made aware that the study focused on judgments about racial categories, and participants were aware of the potential relationships between the stimuli. In addition, the parameters used in the Dovidio et al. (1986) study (stimulus onset asynchronies of $2500 \mathrm{~ms}$ ) may have permitted conscious processing, which could allow intentional suppression of negative attitudes within this paradigm (cf. Judd, Park, Ryan, Brauer, \& Kraus, 1995). Thus, these findings may represent "controlled" rather than "automatic" processing (Posner \& Snyder, 1975).

To examine automatic processes, the present study used a modified version of the subliminal priming procedure introduced by Perdue, Dovidio, Gurtman, and Tyler (1990, Experiment 3). In that experiment, ingroup and outgroup pronoun primes ("we" and "they") were presented very rapidly on a computer screen and then visually masked to prevent participants' awareness of the presence of the prime. The mask was a string of letters designed to cue the category "persons" or, in the control condition, "houses." Similarly to the priming task used by Dovidio et al. (1986), the participant's task was to decide whether the target word that followed could ever describe the cued category, persons or houses. Perdue et al. found that the masked ingroup prime that was presented outside of awareness facilitated responses, relative to the outgroup prime, to positive target words.

In the present experiment, the primes were schematic faces of Black and White men and women and a control prime (X), which were masked by figures representing the cued categories of persons and houses (see also Bargh \& Chen, 1996). The target word stimuli were the evaluatively positive and negative nonstereotypical words used by Dovidio and Gaertner (1993) in their studies of racial associations and evaluations. The present study, using procedures that potentially offer evidence of automatic activation, was intended to complement the findings of Dovidio and Gaertner (1993) and Fazio et al. (1995), who used supraliminal priming techniques, demonstrating implicit bias in the racial attitudes of Whites. It was hypothesized that racial primes would automatically activate biased evaluations among White participants. Specifically, a Racial Prime $\times$ Target Word Favorability interaction was predicted such that participants would respond faster to positive words following a White prime than a Black prime and faster to negative words following a Black prime than a White prime. The relationship between explicit and implicit attitudes was also investigated. To examine whether the activation of implicit attitudes would be moderated by the participants' prejudice, participants also completed explicit (i.e., self-report) 
racial attitudes measures: Brigham's (1993) Attitudes Toward Blacks Scale and McConahay's (1986) Modern Racism scale.

\section{Method}

Participants. Participants were 12 White male and 12 White female undergraduates from a northeastern liberal arts college who participated to fulfill one option of a course requirement. These participants were recruited from a pool of 124 students who completed Brigham's (1993) 20-item Attitudes Toward Blacks Scale and a 5-item version of McConahay's (1986) Modern Racism Scale at the beginning of the semester. Item responses were assessed on 5-point Likert scales. For this sample of 124 students, the Cronbach $\alpha$ for the Attitudes Toward Blacks Scale was .87 and for the Modern Racism Scale was .78. The correlation between these two scales was .74.

Procedure. Participants were informed by a White female experimenter that the study examined how people categorize people and objects. Test stimuli for the categorization task that represented positive and negative nonstereotypic characteristics were based on previous research. Three positive and three negative traits that had been pretested for nonstereotypicality and for favorability $(-3$ to +3$)$ were used. These were the same stimuli employed by Dovidio and Gaertner (1993) and by Perdue et al. (1990, Experiment 3). The three positive traits were good (mean evaluation $=+2.15)$, kind (mean evaluation $=+2.25)$, and trustworthy (mean evaluation $=+2.65)$; the three negative characteristics were bad (mean evaluation $=-2.30$ ), cruel (mean evaluation $=-2.65)$, and untrustworthy (mean evaluation $=-2.20)$.

The main experiment used a procedure that was a variation of a subliminal priming procedure employed by Perdue et al. (1990, Experiment 3), which combined the method of Dovidio et al. (1986), who studied stereotypic and evaluative associations of racial categories, with the method of Bargh and Pietromonaco (1982), who investigated subliminal influences on impression formation. Specifically, participants in the Perdue et al. (1990) study were informed that the study examined "how quickly and accurately people categorize objects and persons." In that experiment, they were told that either the letter string PPPPPP, which represented the category person, or the letter string $\mathrm{HHHHHH,} \mathrm{which}$ symbolized the category house, would be presented on a computer screen and followed by an adjective (the test stimuli). The responses to the person category were of primary theoretical interest.

Perdue et al. (1990) also incorporated into their method procedures for subliminal priming (see Bargh \& Pietromonaco, 1982) using an ingroup designator (we), an outgroup designator (they), and a control prime $(\mathrm{xxx})$ that preceded a person category (PPPPPP) or a house category (HHHHHH) cue. The distance from the participant's eyes to the center of the CRT, where the fixation point (*) was situated, was set at $56 \mathrm{~cm}$ so that the prime stimuli would be presented outside the participant's foveal visual field. Sequentially, participants were (a) initially presented for $75 \mathrm{~ms}$ with a subliminal prime (e.g., we, they, or xxx) that was located $3.6 \mathrm{~cm}$ to the left or right of the fixation point, (b) presented for $250 \mathrm{~ms}$ with a target category cue, PPPPPP for a person or HHHHHH for a house, that visually masked the initial prime, (c) presented with a test word that did or did not commonly describe a person (e.g., drafty), and (d) asked to indicate by pressing the appropriate key (yes or no) whether a test word could ever describe a member of the cued category (i.e., a person or a house).

In the present study, the priming stimuli were schematic faces of Black and White men and women. These stimuli were constructed using Mac-a-Mug software. Two Black male faces, two White male faces, two Black female faces, and two White female faces were systematically constructed to be comparable (at least based on self-reported rating involving 30 White students) in perceived attractiveness, intelligence, friendliness, and likability. Samples of these faces are presented in Fig. 1. These faces, along with a control prime of X, replaced the word primes (we, they, and xxx) used by Perdue et al. (1990). In addition, based on pretesting, the exposure time for these primes was substantially shortened. The exposure time was limited by the hardware used to administer the stimuli, a Power Macintosh 7200 (75 MHz). Specifically, the refresh rate of the monitor resulted in a minimum presentation time of $15 \mathrm{~ms}$ and a maximum of $30 \mathrm{~ms}$. These times are similar to those used for the subliminal presentation of photographs of African American and Caucasian faces by Bargh and Chen (1996) using a Gateway 486 computer with a VGA color monitor (13-26 ms). The $2 \times 1.75$ in. facial 

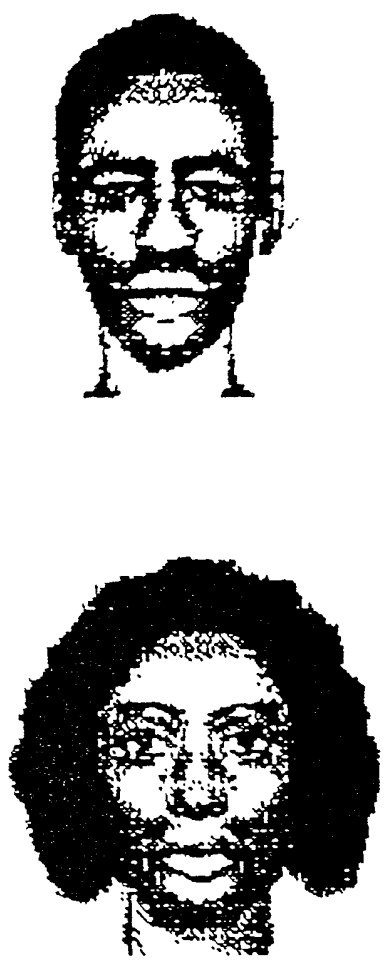
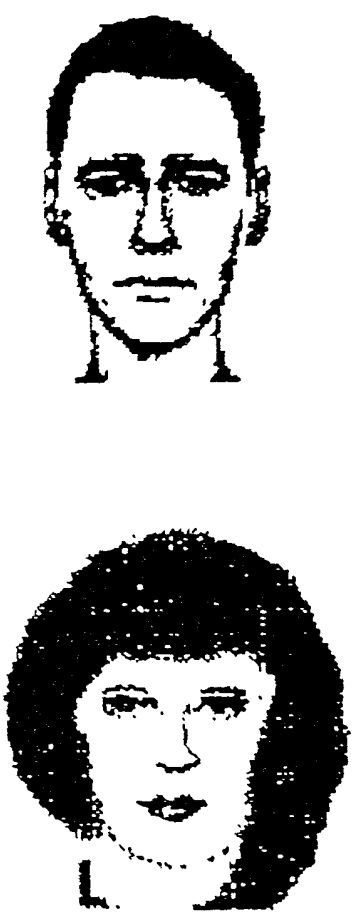

FIG. 1. Samples of schematic faces used as priming stimuli.

primes in the present study were immediately masked by geometrical figures, a "P" within an oval signifying a person or an " $\mathrm{H}$ " within a rectangle representing a house, occupying the same area. Geometrical figures were used as visual masks rather than letter strings (e.g., PPPPPP) in order to fully cover the area of the screen occupied by the facial primes. The cued category, which visually masked the facial or control prime, appeared on the screen for $250 \mathrm{~ms}$. Then the test word (a positive or negative word or one of the six words that do not normally describe persons) was presented until the participant pressed the decision key, or up to $750 \mathrm{~ms}$. There was a $1.5 \mathrm{~s}$ interval between trials.

These exposure times were selected, in part, to produce short SOAs $(<300 \mathrm{~ms})$ between the initial facial or control prime and the test word, which have been identified as a parameter for eliciting automatic (vs controlled) responses with supraliminal presentations (Banaji \& Hardin, 1996; Neely, 1977, 1991). Whereas the short SOAs were used to create conditions requiring efficient processing, subliminal priming was used to establish the automatic criterion of unawareness (Bargh, 1994).

Overall, the experiment consisted of 120 trials. Sixty trials were of theoretical interest. Each of the six person-descriptive words was paired with one White female, one Black female, one White male, and one Black male face presented once to the left of the fixation point and once to the right of the fixation point (48 trials), and each person-descriptive word was paired with the control (X) prime once to the left and once to the right of the fixation point (12 trials). Six house-descriptors (drafty, furnished, leaky, roomy, thatch, wooden) were used for the 60 distractor trials (48 trials pairing nonperson descriptors with the face primes, plus 12 trials with the control prime). Participants were familiarized with the procedure and equipment before participating. To allow participants to become familiar with the task, the first six trials were arranged not to be trials of theoretical interest. Two orders of trials were used across subjects; one was a randomly determined order (except for the first six trials) and the 
other was the reverse order. In addition, the locations of the "yes" and "no" keys ( $\mathrm{Z}$ and $\mathrm{M}$ on the keyboard) were counterbalanced across subjects.

The primary dependent measure was the response latency of each prime-category-test word combination. An error was scored if the participant gave no response to one of the person-descriptive test words on a trial in which the person category was cued (the P within the oval symbol) or if, following the person-category cue, the participant indicated that the person-descriptive test word could not describe a person. Response latencies for the trials of theoretical interest that were three or more standard deviations beyond each participant's mean response times were identified as outliers (less than $2.5 \%$ of the distribution of response times) and excluded from the analysis; the remaining response times were subjected to a logarithmic transformation (see Blair \& Banaji, 1996; Ratcliff, 1993). The transformed values associated with each of the three positive and negative stimulus words were averaged, and deviation scores were created by subtracting the transformed response latencies for the positive and negative control prime conditions from the times for each of the four face-prime conditions (reflecting the Race $\times$ Sex of prime combinations). Analyses were conducted on the transformed data, but the untransformed means (in $\mathrm{ms}$ ) are presented in figures and reported in the text.

To determine whether participants were, in fact, unaware of the subliminal primes (Greenwald, Klinger, \& Liu, 1989), participants were probed about the masked primes during debriefing. No participant reported that he or she had seen a face prime. In addition, a pilot guessing study (see Bargh \& Pietromonaco, 1982; Perdue et al., 1990) was conducted in which 12 participants were run through a 48-trial procedure similar to the main experiment but were asked to guess what the initial prime was. Comparable to the rates reported by Bargh and Pietromonaco (1982), Devine (1989), and Perdue et al. (1990) with words as primes, on only 17 of the 576 trials (3\%) did these participants accurately identify the prime. These data support the results of the debriefing and indicate that the conditions for automatic priming without conscious awareness were met.

\section{Results}

Preliminary analysis revealed an overall error rate that was low $(<2 \%)$ and not systematically related to the experimental conditions. A 2 (Participant Sex) $\times 2$ (Stimulus Order) $\times 2$ (Race of Facial Prime: White and Black) $\times 2$ (Sex of Facial Prime) $\times 2$ (Favorability of Target Word: Positive and Negative) analysis of variance with repeated measures on the last three independent variables was performed on the deviation scores from baseline. The predicted Race Prime $\times$ Target Word Favorability interaction was obtained, $\mathrm{F}(1,20)=7.32, p<.014$, uncomplicated by any higher-order interactions. The untransformed means for the White, Black, and control prime conditions are illustrated in Fig. 2. Planned comparisons revealed, as predicted, that response times to negative target words were significantly faster following the Black than following the White prime, $M \mathrm{~s}=795 \mathrm{vs} 908 \mathrm{~ms}$, Deviation $M \mathrm{~s}=-72 \mathrm{vs}+41 \mathrm{~ms}, t(23)=3.91, p<.001$. This effect seemed to reflect a facilitation effect relative to the control condition for the Black prime. Response times to negative words were faster following the Black prime than the control $(\mathrm{X})$ prime, $t(23)=2.89, p<.008$; there was no significant difference in response times between the White prime and the control prime conditions, $p>.44$. Also as predicted, response times to positive words were significantly shorter following the White than following the Black prime, $M \mathrm{~s}=701 \mathrm{vs} 755 \mathrm{~ms}$, Deviation $M \mathrm{~s}=-123 \mathrm{vs}-69 \mathrm{~ms}, t(23)=2.26, p<.033$. This result reflected primarily a facilitating effect for the White prime. Response times to positive words were significantly faster following the White prime than 


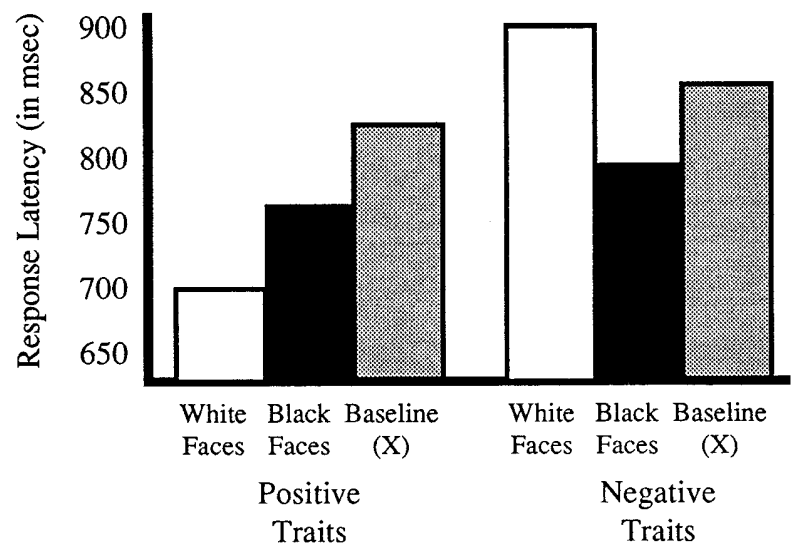

FIG. 2. Experiment 1: The effects of racial prime and target word favorability on response latencies.

following the control prime, $t(23)=4.16, p<.001$. Response times were somewhat but not significantly $(p>.10)$ faster following the Black prime than the control prime (see Fig. 2).

To examine the relationship between explicit measures of prejudice and response latency measures of attitudes, scores on the Attitudes Toward Blacks Scale $($ mean $=2.89, S D=0.32)$ and on the Modern Racism Scale $($ mean $=1.57$, $S D=0.50)$ were correlated with response latency measures of bias. The primary measure used in this and in the subsequent experiments represented the degree to which participants responded faster to negative words following the Black prime than following the White prime, combined with the degree to which participants responded faster to positive words following the White prime than following the Black prime. This measure is the weighted combination (i.e., $+1,-1,-1,+1$ ) of response latencies associated with the Race Prime $\times$ Target Word Favorability interaction for each participant. Higher scores indicate greater racial bias. This response latency measures was somewhat, but not significantly, correlated with Modern Racism scores $(r[22]=.15, p=.48)$ and Attitudes Toward Blacks scores $(r[22]=.28, p=.19)$. In addition, four supplementary measures were computed for this and the subsequent studies representing each of the four possible simple effects for the $2 \times 2$ interaction. As illustrated in Table 1, the correlations between these measures and Modern and Old-Fashioned Racism were of similar magnitude and also not statistically significant.

\section{Discussion}

The results of Experiment 1 complement the findings of Dovidio and Gaertner (1993) and Fazio et al. (1995), who found evidence of implicit negative racial attitudes among Whites toward Blacks using supraliminal priming techniques. As predicted, in Experiment 1 White participants responded faster to positive words following a White prime than following a Black prime and faster to negative 
TABLE 1

Correlations between Response Latency Measures of Bias and Self-Report Measures of PREJUdice

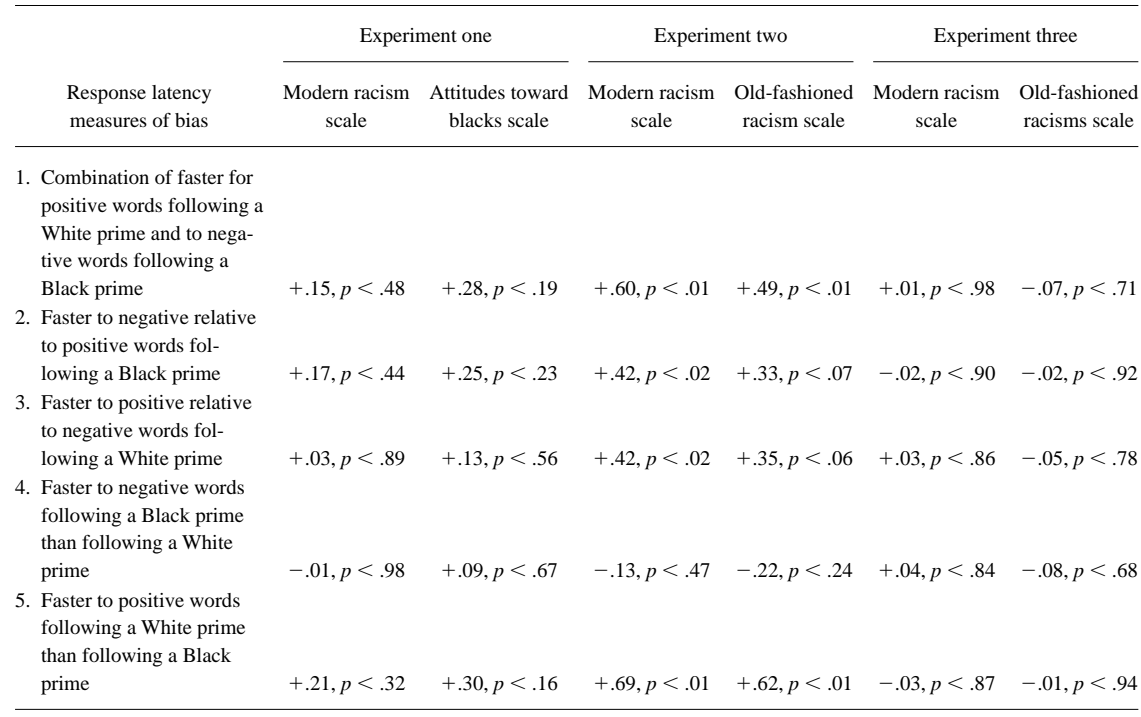

words following a Black than following a White prime. Furthermore, the use of facial primes rather than semantic primes (e.g., Blacks, Whites) provides more direct evidence that these are implicit racial attitudes, not simply connotations of the colors black and white (Williams, Tucker, \& Dunham, 1971).

The response latency measures of evaluative activation, representing implicit racial attitudes, were only weakly correlated with explicit measures of prejudice. This finding is consistent with the results of Fazio et al. (1995) and offers further evidence of implicit evaluative biases that may not be predicted from self-report measures of prejudice. This dissociation between explicit and implicit measures of racial bias is also consistent with the contemporary perspectives on racial attitudes, such as Devine's (1989) disassociation framework, the aversive racism perspective (Gaertner \& Dovidio, 1986), and symbolic (Sears, 1988) and modern racism (McConahay, 1986) theories.

If there is a dissociation between explicit and implicit attitudes, as the work of Fazio et al. (1995) and Experiment 1 suggest, then self-report and response latency measures of attitudes may differentially predict race-related behaviors. For example, as proposed by Fazio et al. (1995), response latency techniques may represent "an indirect, unobtrusive measure of attitude" (p. 1014). Alternatively, self-reported attitudes and response latency measures of attitudes may both be valid measures of attitudes (one conscious, the other unconscious) that predict different types of behaviors. Experiment 2 therefore further explored the implicit racial attitudes and the relative predictive validity of self-report and response latency measures on race-related responses. 


\section{EXPERIMENT 2}

Research concerning attitudes as predictors of behavior has moved from the issue of whether there is a relationship to what the nature of that relationship is (Fazio, 1990; Zanna \& Fazio, 1982). The nature of the attitude-behavior relationship may be affected by the way attitudes are measured and the type of behavior that is being examined. With respect to measuring attitudes, Dovidio and Fazio (1992) have argued that one difficulty in assessing attitudes for socially sensitive issues, such as racial prejudice, is that people may consciously alter their responses to conform to prevailing norms (Gaertner \& Dovidio, 1986). With respect to behavior, Fazio (1990) proposed that there are fundamental differences between behavioral responses that are based on conscious deliberation (involving an analysis of costs and benefits) and responses that are based on spontaneous reaction to an attitude object or issue. Experiment 2 examined how conscious (explicit) and nonconscious (implicit) racial attitudes predict Whites' spontaneous and deliberative interracial responses.

Theoretically, racial attitudes may be examined at three different levels. First, there may be public attitudes. Individuals may publicly express socially desirable (nonprejudiced) attitudes even though they are aware that they privately hold other, more negative attitudes (Sigall \& Page, 1971; Roese \& Jamieson, 1993). Direct measures of traditional racist attitudes, such as McConahay's (1986) Old-Fashioned Racism Scale, are very susceptible to this type of impression management and thus may reflect this type of orientation (McConahay, Hardee, \& Batts, 1981). Second, there may be personal, conscious aspects of racial attitudes. In contrast to public attitudes that are related to impression management, these personal attitudes are influenced by an individual's private standards and ideals (Devine \& Monteith, 1993). For example, according to the aversive racism perspective (Gaertner \& Dovidio, 1986), Whites may express attitudes that are consistent with their nonprejudiced self-image but that do not reflect their unconscious negative feelings toward Blacks. Indirect self-report measures of prejudice, such as McConahay's (1986) Modern Racism Scale, have been designed to minimize public impression management and produce a more valid measure of personal attitudes (cf. Fazio et al., 1995). Modern racism is presumed to be a more subtle manifestation of prejudice in that bias is expressed in rationalizable ways that do not challenge a person's nonprejudiced self-image (see, however, Fazio et al., 1995). At a third level are implicit attitudes (Greenwald \& Banaji, 1995), unconscious feelings and beliefs which are often different from personal or public attitudes (Experiment 1; see also Fazio et al., 1995). As illustrated in Experiment 1, response latency techniques may be used to assess implicit attitudes.

Which level represents a White person's "true" racial attitude? We propose that each of these levels represents a "true" aspect of an attitude and that the central question should be instead, "Which aspect of an attitude best predicts which type of behavior?" Our general position, which is guided by Fazio's MODE Model, is that implicit (unconscious) aspects of an attitude will best predict spontaneous 
behavior (see also Bargh \& Chen, 1996), personal attitudes will best predict private but controlled responses (Crosby, Bromley, \& Saxe, 1980), and public aspects of attitudes should best predict behavior in situations in which social desirability factors are salient. This framework is consistent with Fazio et al.'s (1995) recent research demonstrating the predictive validity of response-latency measures of racial attitudes. Direct ratings concerning the legitimacy of the Rodney King verdict and the illegitimacy of the anger of the Black community were correlated mainly with self-reported prejudice (Modern Racism); these responses did not correlate with the response-latency measure. However, the response-latency measure correlated more highly with the relative responsibility ascribed to Blacks and Whites for the tension and violence that ensued after the verdict, perhaps a more subtle and indirect manifestation of racial bias, than did the Modern Racism scores. Experiment 2 examined, in particular, the relationships among Old-Fashioned, Modern, and response-latency measures of Whites' racial attitudes and spontaneous and deliberative race-related decisions.

The study involved two ostensibly unrelated parts: (1) measures of racial attitudes and (2) race-related decisions. The measures of racial attitudes included the response-latency task of Experiment 1 and two self-report measures. The self-report measures were McConahay's (1986) Old-Fashioned Racism Scale, which assesses overt bias, and Modern Racism Scale, which was designed to be an indirect measure of subtle personal prejudice. The decision-making part of the present research included tasks that varied along a deliberative-spontaneous dimension (Fazio, 1990). Two of the tasks involved juridic judgments of the guilt or innocence of Black male defendants. These are deliberative tasks and, based on pilot research, perceived as public measures of racial attitudes. Spontaneous responses were measured in a variation of Gilbert and Hixon's (1991) wordcompletion task. Participants performed this task under the "cognitive busy" conditions used by Gilbert and Hixon (1991, Expt. 1) while alternating decision tasks. On alternate trials, participants classified faces presented on a computer as Black (African American) or White (which served as a prime for the following trial) and completed words by pressing an appropriate key (e.g., an "a" or "u" to complete "B_D"). The measure of racial bias was the extent to which participants created more negative words following Black than White faces.

It was predicted that the response latency measure of implicit attitudes would predict answers to the word-completion task. This task requires rapid and relatively spontaneous responses under demanding circumstances that likely inhibit conscious control of responses motivated by social desirability concerns or the desire to maintain personal egalitarian standards. As Fazio et al. (1995) posited, "It is for such relatively uncontrollable classes of behavior that the effects of any automatically activated personal evaluations are likely to be most apparent" (p. 1020). Alternatively, it was hypothesized in the present experiment that self-report measures of prejudice would significantly predict juridic judgments, for which motivations to comply with both social norms and personal standards of egalitarianism would be salient, and there would be ample time to consider these 
factors in formulating a response. For this task, participants would have both the opportunity and motivation (see Fazio, 1990) to act in a manner consistent with their professed racial attitudes.

\section{Method}

Participants. Twenty White male and 13 White female first- and second-year undergraduates participated to complete one option of a course requirement.

Procedure. The study consisted of two, ostensibly unrelated, parts. Participants were informed that the two parts were being conducted by different groups working on different research projects. Participants were further informed that students were scheduled for both studies because each took one-half hour to complete; performing both would enable the participant to earn a full hour's research participation credit.

The first part of the study was again introduced by a White female experimenter as an experiment about how people categorize persons and objects. It closely resembled the priming procedure used in Experiment 1. The major differences were that (1) the control prime (X) was not included in order to reduce the amount of time participants performed the priming task, and (2) only male faces were used as primes, to be consistent with the juridic judgments in the second phase of the experiment that involved only male defendants. Theoretically, group stereotypes may be associated more strongly with men than with women (Eagly \& Kite, 1987) and possibly intergroup attitudes, but no differences for sex of the target were obtained in Experiment 1. The test stimuli were exactly the same: three positive traits (good, kind, and trustworthy), three negative characteristics (bad, cruel, and untrustworthy), and the six nonperson descriptors. The same instructions and parameters for the presentation of the stimuli were also used. The elimination of the control prime reduced the number of trials presented from 120 in Experiment 1 to 96 in this experiment. The 48 trials of theoretical interest involved each of the six person-descriptive words paired twice with each White male and Black male face presented, once paired on the left of the fixation point and once on the right of the fixation point. Two female participants reported during debriefing that they saw some face primes during the task. Their data were excluded from subsequent analyses. Response latencies for the trials of theoretical interest that were three or more standard deviation points beyond each participant's mean response times were identified as outliers (less than $2.0 \%$ of the distribution of response times) and excluded from the analysis. The remaining response times were log transformed. The transformed values associated with each of the three positive and negative stimulus words were averaged for Black and White prime conditions.

Following the priming task, participants completed an "opinion questionnaire" that included a 7-item Old-Fashioned Racism Scale (McConahay, 1986) and a 7-item Modern Racism Scale. Participants responded to these items on 5-point Likert scales. For the participants in this study, the Cronbach $\alpha$ was .79 for the Old-Fashioned Racism Scale $(M=1.55, S D=.64)$ and .88 for the Modern Racism Scale $(M=1.85, S D=.86)$.

After completing this phase of the study, participants were escorted by another White female experimenter to a cubicle in another part of the research area. They were then informed that this project investigated how people make decisions about others under different circumstances. This second session involved two types of tasks presented in counterbalanced order across subjects. One set of tasks, which was intended to foster deliberative decision-making, involved simulated juridic judgments. Participants were informed that the "purpose of this part of the study is to learn more about how individuals make decisions about jurors. You will be presented with two cases and asked to indicate a verdict for each. . . For each case, you have been given a summary of the crime, the prosecution's evidence, and the defense's evidence. Please read the materials carefully." The cases were adapted from materials used in studies by Bodenhausen and Lichtenstein (1987) and Faranda and Gaertner (1979). Judgments were reported on 11-point scales ranging from 0, indicating "definitely innocent," to 10, indicating "definitely guilty." One case involved "a 30-year-old, Black man" who was a defendant in a robbery and murder case in which the victims were a White storekeeper and his granddaughter. The defendant was identified by a witness who "had been standing in the backroom during the robbery" and who later pursued the assailant and "reported seeing the robber run into an 
apartment house two blocks away." The other case involved "a 27-year-old Black male" defendant who was accused of attacking a White man in an alley behind a bar. The victim and defendant "were observed quarrelling by other bar patrons earlier in the evening," and the defendant "was seen leaving the bar about 10 minutes before the attack occurred." Responses to these two cases were positively correlated, $r(29)=.39, p<.032$, and were averaged together for subsequent analyses.

The other task in this phase of the research, which was designed to assess more spontaneous responses, was a word-completion task based on the method used by Gilbert and Hixon (1991). In the cognitive-busy condition of Gilbert and Hixon's (1991, Experiment 1) study, participants were asked to complete word stems (e.g., N_P) while attempting to remember an 8-digit number. Participants in the present study were informed that this segment of the session involved sequentially making decisions on two different and unrelated tasks, a "multiple decision task." It was explained that in many occupations (such as air-traffic controller) it is necessary for people to handle "simultaneous task demands." The task used in the present study was a variation of Gilbert and Hixon's (1991) cognitive-busy procedure in which participants were asked to remember an 8-digit number while performing the word-completion task. In addition, cognitive demand was created by asking participants to perform two different tasks sequentially on alternate trials under limited time constraint. These tasks were presented on the computer screen. The first task in each pair required the participant to categorize a male schematic face (including the same faces used as the primes in the response latency study) as Black or White by pressing an appropriate key. This task was used to provide a racial prime. The second task in each pair, which immediately followed the participant's response on the categorization task, was to complete a word by typing in the missing letter. Participants had $10 \mathrm{~s}$ to make this decision before the next trial began.

The response of interest was whether the participant provided a letter that completed a positive or negative word. Word stems were chosen based on pretesting (see Gilbert \& Hixon, 1991) that indicated that they could be completed as positive, neutral, or negative words (i.e., with more than one probable answer). For example, B_D completed with an "a" would produce a negative word, but completed with an "i" would produce a neutral word. The word stem "LO_AL" could be completed with a " $y$ " creating a positive word or a "c" creating a neutral word. There were 24 word stems of this type, 12 paired with a Black face and 12 paired with a White face. The pairings were counterbalanced across two sets of stimuli. The word stems that were used were HA_E, RU_E, PRO_ANE, _IGHT, _URE, _INISTER, LO_D, GO_D, POLI_E, BU_, MA_,_ITY, W_RM,_AGE, WI_E, S_ORT, LA_Y, _RUNK, CLEA_, B_D, S_AVE, MEA_, LO_AL, and POO_. A pool of potential word completions were generated during pretesting, and these responses were then identified by participants in the pilot study $(n=12)$ as positive, negative, or neutral words. Two raters, unaware of the primed racial category, coded the word completions of each participant in the present study as a positive $(+1)$, neutral $(0)$, or negative $(-1)$ from this predetermined list of potential word completions. When a word completion occurred that was not on the list (approximately $2 \%$ of the time), the coders reached agreement on the score assigned. Scores for the words paired with Black and White faces were separately summed and then subtracted from one another. More positive scores represented more positive word completions following the White faces (or, alternatively, more negative scores following Black faces).

\section{Results}

The analyses examined results for the priming task, then the relationships among explicit and implicit measures of prejudice, and finally the relationship between the explicit and implicit measures of prejudice and participants' judgments of guilt of Black defendants and race-related differences in word completions.

Priming and response latencies. Preliminary analysis demonstrated that the overall error rate was low $(3.0 \%)$ and not systematically related to the experimental conditions. For the latency measure, the 2 (Participant Sex) $\times 2$ (Stimulus 
Order) $\times 2$ (Race of Facial Prime: White and Black) $\times 2$ (Favorability of Target Word: Positive and Negative) analysis of variance, with repeated measures on the last two independent variables demonstrated the predicted Race Prime $\times$ Target Word Favorability interaction, $F(1,27)=5.51, p<.026$. This effect was uncomplicated by any higher-order interactions. As anticipated, response times to negative target words were significantly faster following the Black prime than following the White prime, $M \mathrm{~s}=751$ vs $883 \mathrm{~ms}, t(30)=4.16, p<.001$. Response times were slightly, but not significantly, faster to positive words following the White primes than following the Black primes, $M \mathrm{~s}=660$ vs 663 $\mathrm{ms}, p>.62$.

Implicit and explicit measures of prejudice. Unlike Experiment 1 and previous research (e.g., Fazio et al., 1995), there were positive correlations between the explicit measures of prejudice employed in this experiment and response-latency measures of bias (see Table 1). In particular, the primary response-latency measure of bias correlated $.60(p<.01)$ with Modern Racism and $.49(p<.01)$ with Old-Fashioned Racism. Old-Fashioned Racism and Modern Racism were highly related, $r(29)=.78, p<.001$.

Prejudice, juridic judgments, and word completions. Beyond providing a replication of Experiment 1, the primary focus of this experiment was to investigate the relationships between implicit and explicit measures of bias and subsequent race-related judgments. It was hypothesized that explicit measures of prejudice would primarily predict the deliberative juridic judgments whereas response-latency bias (represented by the sum of the two components- the extent that participants responded slower to positive words and faster to negative words after a Black prime than a White prime) would predict the results of the word-completion task, which required more spontaneous actions. The pattern of Pearson correlations was generally consistent with these hypotheses. Ratings of Black defendant guilt across the two cases was significantly related to OldFashioned Racism scores, $r(29)=.51, p<.003$, and Modern Racism scores, $r(29)=.38, p<.033$, but not to response-latency bias, $r=.02$. In contrast, response-latency bias was correlated with more negative word completions following Black than following White faces, $r(29)=.48, p<.007$, whereas Old-Fashioned Racism, $r(29)=.10, p<.583$, and Modern Racism, $r(29)=.14$, $p<.462$, did not. Ratings of guilt and word-completion bias were nonsignificantly, negatively related, $r(29)=-.15, p<.423$.

In addition, to evaluate the predictions, regression equations were computed in which the dependent variables were, separately, ratings of guilt and wordcompletion bias, and the independent variables were Old-Fashioned Racism scores, Modern Racism scores, and response-latency bias considered simultaneously. For the equation for ratings of guilt, $F(3,27)=4.68, p<.01$, Old-Fashioned Racism was the only significant predictor, $\beta=.56, p<.034$. Modern Racism had a nonsignificant positive relation, $\beta=.15, p=.582$, and response-latency bias had a nonsignificant negative effect, $\beta=-.35, p=.082$. For word-completion bias, $F(3,27)=43.41, p<.04$, response-latency bias was 
the only significant predictor, $\beta=.63, p<.005$. When the predictor variables were considered simultaneously, Old-Fashioned Racism $(\beta=-.04, p=.871)$ and Modern Racism $(\beta=-.20, p=.483)$ had nonsignificant negative relations. ${ }^{1}$ These findings are consistent with predictions.

\section{Discussion}

The results were consistent with our predictions and supported a multidimensional view of racial attitudes. Explicit and implicit racial attitudes predicted race-related decisions - but different ones. As expected, ratings of the guilt of a black defendant were correlated most strongly with Old-Fashioned Racism ratings but also significantly with Modern Racism. As with Fazio et al.'s (1995) findings for ratings about the Rodney King verdict, ratings of guilt were not predicted by the response-latency measure. In contrast, bias in the wordcompletion task, a more spontaneous type of response, was significantly predicted by response-latency scores and not by either self-report measure of prejudice. The relationship between the response-latency measure of bias and the wordcompletion task, which was performed with a high level of cognitive busyness, reflects the efficiency of implicit attitude activation. Efficiency, defined as a process requiring few attentional resources, is a fundamental quality of automatic activation (Bargh, 1994).

Experiment 2, which generally replicated the pattern of bias in implicit racial attitudes of Experiment 1, extends our previous research and complements the conclusions of Fazio et al. (1995) by demonstrating that variability in response latencies may reflect systematic and meaningful individual differences in implicit attitudes. However, we note some inconsistencies and limitations in the results. First, although it is plausible that implicit and explicit measures of attitudes may correlate to some extent, particularly if they are rooted in common experiences and socialization, the magnitude of the correlation of response-latency bias with Modern and Old-Fashioned Racism scores was unexpectedly high given the results of Experiment One, other previous research (Fazio et al., 1995), and the demonstrations of dissociations between implicit and explicit cognition more generally (Wegner \& Bargh, 1997). Second, we recognize that although our results were consistent with predictions derived from Fazio's (1990) MODE Model, our findings are preliminary, and support should be interpreted with some

${ }^{1}$ Because of the high correlations among the three predictor variables (i.e., Modern Racism, Old-Fashioned Racism, and response latency bias), supplementary analyses were performed. These analyses do not alter the conclusions from the primary analyses. For ratings of guilt, for example, the $\beta$ for response latency bias was $.01(p=.948)$ when it was the only predictor variable. This finding suggests that the marginally significant $\beta$ of $-.35(p=.082)$ that was obtained when all three predictors were considered simultaneously may be an artifact of multicollinearity among the independent variables. Regression analyses were also performed entering only one of the explicit measures of prejudice (i.e., Modern or Old-Fashioned Racism) simultaneously with the response latency measure. The results are the same except that when Modern Racism is considered without Old-Fashioned Racism, it is a significant predictor of ratings of Black defendant guilt, $\beta=.58$, $p<.010$. 
caution. Deliberative and spontaneous behaviors, in general, are difficult to define theoretically or operationally and may involve other dimensions. In the present study, for example, the juridic judgment tasks and the word-completion task differed along the deliberative/spontaneous dimension but varied also in terms of the nature of the decision (e.g., legal and person-specific vs category-based). One possible interpretation might be that implicit attitudes are irrelevant when it comes to important social behaviors, for which self-reported attitudes are important.

In addition, although judgments like those reflected in simulated juridic decisions have been used as behavioral intentions in previous research (e.g., Brigham, 1971), they may not fully represent the responses that might occur during actual trials (Costanzo \& Costanzo, 1994) or in more common face-to-face interaction. However, indicating some degree of external validity, the results of analog studies of racial biases in juridic decisions generally parallel the findings of archival research on the outcomes of actual court cases (Johnson, 1985). Furthermore, although a measure of spontaneous response, it could be reasonably argued the Gilbert and Hixon (1991) word-fragment completion task reflects another measure of racial prejudice more than it does discriminatory behavior. Even so, the significant correlation between the response-latency measure and word-completion responses and the weak relationship between the self-report measures of racial attitudes and word-completion responses offer some support for the implicit-explicit attitude dichotomy outlined by Greenwald and Banaji (1995). Nevertheless, given the plausible alternative interpretations of Experiment 2 and the disparity in correlations between implicit and explicit measures of attitudes in the first two experiments, a third study was performed that again used response latency and self-report measures of prejudice but involved responses to specific black and white persons in face-to-face interaction.

\section{EXPERIMENT 3}

This third experiment investigated how implicit and explicit measures of racial attitudes may differentially predict the responses of White participants to Black and White partners during face-to-face interaction. As a measure of explicit attitudes, participants were asked to evaluate both other interactants on a series of rating scales. Such direct measures have been identified as being reactive measures that are sensitive to racial concerns and can produce deliberative attempts to appear nonprejudiced among people motivated to appear so (Crosby et al., 1980; Dovidio \& Fazio, 1992; Gaertner \& Dovidio, 1986; Sigall \& Page, 1971). Nonverbal behaviors were used to represent more spontaneous forms of behavior. As Fazio et al. (1995) propose, "Nonverbal behavior, in particular, may be subject to 'leakage' of negativity that an individual is experiencing, despite the individual's effort to behave in a nonprejudiced manner" (p. 1026).

Crosby et al. (1980) identified nonverbal behavior as a viable, unobtrusive measure of racial attitudes. They note, "Because nonverbal behavior generally lies outside of conscious awareness and control, nonverbal behavior may be 
considered less subject to social desirability effects than are verbal attitude reports" (p. 555). Consistent with this assumption, their review of the literature revealed, first, that there was stronger evidence of racial bias among studies using nonverbal measures than those using self-report measures, and second, that for studies employing both types of measures there was a dissociation between verbal and nonverbal measures. Crosby et al. concluded that the "nonverbal behavior studies of racism imply that whites still discriminate against blacks in terms of behaviors that lie largely out of awareness. This is true even for whites who do not discriminate in terms of behaviors that fall under more conscious control, such as verbal reports" (p. 556). We acknowledge that nonverbal behaviors can be deliberately regulated with some success, and this control can be improved by practice, experience, and knowledge (DePaulo, 1992; DePaulo \& Friedman, 1997). Nevertheless, people generally monitor and control their nonverbal behaviors less frequently and effectively than they do their verbal behaviors (Harper, 1985). Thus, nonverbal behaviors represent relatively spontaneous social behaviors.

Participants in Experiment 3 took part in two ostensibly unrelated sessions. The first session, as in Experiment 2, was designed to assess implicit and explicit racial attitudes. The second session was described as part of an interview requirement for a psychology course. During this session, participants were asked to discuss a series of questions presented by a Black female and a White female interviewer who behaved in a preprogrammed, well-rehearsed manner. At the end of the session, the participants were asked to evaluate both interviewers-a deliberative response to these particular people. In addition, the session was videotaped and participants' nonverbal behaviors were later coded. These behaviors represented relatively spontaneous reactions to the interviewers.

In particular, two measures of nonverbal behavior were studied in Experiment 3. One was visual contact or gaze. Higher levels of visual contact (i.e., percent of time spent looking at another) reflect greater attraction (Exline, 1972; Kleinke, 1986; Kleinke, Meeker, \& LaFong, 1974; Harper, 1985), intimacy (Rubin, 1970), and respect (Dovidio, Brown, Heltman, Ellyson, \& Keating, 1988; Efran, 1968; Efran \& Broughton, 1966; Fugita, 1974). The other measure was blinking. Higher rates of blinking have been demonstrated to be related to higher levels of negative arousal and tension (Doering, 1957; Exline, 1985; Kanfer, 1960). Both of these nonverbal behaviors are particularly difficult to monitor and control (see Ellyson \& Dovidio, 1985).

Following the rationale developed for Experiment 2, it was predicted that the explicit measures of prejudice, Modern and Old-Fashioned Racism, would primarily predict bias in the evaluations of Black relative to White interviewers. In contrast, the response-latency measure of negative racial attitude was expected to be the best predictor of nonverbal reactions-specifically higher rates of blinking and lower percentages of visual contact with the Black relative to the White interviewer. 


\section{Method}

Participants. Participants were 14 White male and 19 White female second-, third-, and fourth-year undergraduates who were paid five dollars for their participation.

Procedure. This study also consisted of two supposedly unrelated parts. Participants were informed that the two parts were being conducted by different experimenters who were pooling their funds to recruit participants.

The first session was again introduced by a White female experimenter as an experiment about how people categorize persons and objects. Its procedures and materials were identical to those used in Experiment 2. Participants performed the priming task first and then completed the "opinion questionnaire" that included a 7-item Old-Fashioned Racism Scale (McConahay, 1986) and a 7-item Modern Racism Scale. Participants responded to these items on 5-point Likert scales. The Cronbach $\alpha$ for participants in this study was .69 for the Modern Racism Scale. The Cronbach $\alpha$ for the Old-Fashioned Racism Scale for this sample was unexpectedly low, .32, perhaps due to the restricted range of responses. The mean score on the 1-5 scale was 1.28 with a standard deviation of 0.34 . Two-thirds of the respondents had scores of 1.00, 1.14, or 1.28 - the three lowest possible scores. The mean score for the Modern Racism Scale was 1.67, with a standard deviation of 0.51. Old-Fashioned and Modern Racism scores were highly correlated, $r(31)=.74, p<.001$.

After completing the first phase of the research, participants were met by a second White female experimenter and escorted to another room to begin an ostensibly unrelated study. They were informed that this session was part of an "interview practicum" for a psychology class and that they would be interviewed by one or more advanced psychology students. The experimenter presented an overview of the procedure and explained that the session would be videotaped for later evaluation. The room contained two chairs separated by a 3-ft-square table. One camera was situated behind the participant's chair and directed toward the interviewer's chair; another camera was located behind the interviewer's chair and directed toward the participant's chair. These images and the conversation were recorded using equipment in an adjacent cubicle.

After answering any questions the participant posed, the experimenter announced that she would now get the interviewer. Each participant interacted with two interviewers, one Black female and one White female college student, in counterbalanced order across participants. Two different pairs of Black and White interviewers were used in the present research. Each interviewer asked the participant to respond to one question or situation. These tasks were pretested to insure that they were involving and generated fairly lengthy responses and that men and women (as well as Blacks and Whites) would report being and be perceived as being equally knowledgeable about the topic (see Dovidio et al., 1988).

Two set of questions were used for each session. The two questions in one set were: (1) Dating in the 1990 's has some advantages and disadvantages to dating in earlier eras. Please consider and discuss what you personally feel are these advantages and disadvantages; and (2) First-year college students often bring more than they need to college. Please identify three or four things that are most essential for first-year students to bring, as well as the three or four things that first-year students are most likely to bring to college and do not need.

The two questions in the other set involved hypothetical situations in which participants were asked to make decisions: (1) You are in a boat with four other people. The boat begins to sink, and the closest land is five miles away. ... The lifeboat will only carry three people. . . List, in order (1 to 5) the priority of people for the lifeboat: you, a 60-year-old male doctor, a pregnant woman, a 5-year-old boy, the boy's father; and (2) A husband and wife are recently married. The husband tells the wife he must go on a business trip.... After he leaves, the distraught wife asks the ferryman . . to take her to the other side of the river where she visits an old boyfriend and spends the night with him. The next morning ... when she reaches the ferry she realizes that she has no money; the ferryman does not let her on board. ... She runs to an old bridge, stumbles apparently accidentally, and falls into the river and drowns. Rank order the following people in terms of responsibility for her death: husband, self, ferryman, boyfriend, husband's job. The particular set of questions assigned to Black and White 
interviewers was varied across participants, as well as the order in which the two questions in each set were asked.

After introducing herself, the interviewer presented each question once verbally, asked the participant "to think for a minute or so" about his or her answer before responding, and then repeated the question. Interviewers were trained to maintain a steady gaze while the participant responded, looking away only to avoid appearing to stare (Exline, 1972). Interviewers were also instructed to nod periodically to show responsiveness and, if the participant completed her response in less than one minute, to ask, "Can you elaborate [or expand] on that?" After the participant finished his or her response, the interviewer excused herself and left the interview room to retrieve the experimenter. The experimenter returned and briefly informed the participant of the second interview. She left and returned with the second interviewer. Participants were not informed of how many interview questions or interviewers there would ultimately be.

At the end of the second interview session, the experimenter returned with questionnaires "to assess participants' responses to the interviews." Participants were asked to evaluate both interviewers, sequentially by the order of their appearance, on 7-point semantic differential scales adapted from previous research (Dovidio et al., 1988) and designed to assess evaluation of the interviewers. Factor analyses with varimax rotation, performed separately on ratings of the Black and White interviewers, each demonstrated that the evaluative items loaded on the same factor. These items were then averaged to form an evaluative score for each interviewer. The evaluative items were unlikable-likable and insincere-sincere (Cronbach $\alpha$ for the White interviewer $=.59$; for the Black interviewer $=.60$ ). A relative evaluation score was then computed by taking the difference between evaluative ratings of the White and Black interviewers. To assess self-perceptions of their behavior, participants were also asked to rate, using the same set of semantic differential items, how they behaved toward each interviewer. The Cronbach $\alpha$ for the evaluative items was .79 for interaction with the White interviewer and .83 for interaction with the Black interviewer. ${ }^{2}$ A relative score was also computed for this measure.

Nonverbal behaviors were coded from the videotapes from the angle over the interviewer's shoulder using the procedures outlined in Dovidio et al. (1988). With respect to the behavior of the participants, two coders, uninformed about the hypotheses and unaware of the race of the interviewer, independently recorded (1) the amount of time (in seconds) that participants responded to each question, the amount of time (in seconds) they made visual contact with the interviewer during that period, and the number of times the participant blinked during that period. Reliability, as determined by the intraclass correlation coefficient, was .99 for speaking time with the White interviewer and .99 for speaking time with the Black interviewer, .85 for visual contact with the White interviewer and .90 for visual contact with the Black interviewer, and .96 for blinking with the White interviewer and .97 for blinking with the Black interviewer. The average for the two coders on each measure was computed. The rate of blinking was calculated as the number of blinks divided by the time of the response period. The percent of time in visual contact was the time in visual contact divided by the response time, which was then multiplied by 100 . The behaviors of the interviewer were also coded. There was no difference across the interviewers in visual contact, the number and rate of nods, and the number of times the interviewer prodded the participant for elaboration on the response. In addition, preliminary analyses revealed no differences in results between the two sets of interviewers. Consequently, this factor is not included in the analyses reported.

2 The factor analyses of the semantic differential ratings of the interviewers and of participants' own behaviors also yielded a second, potency dimension. The potency items were submissive-dominant, powerless-powerful, irresponsible-responsible, and confused-confident. For interviewer ratings, the Cronbach $\alpha$ was .73 for the White interviewer and .74 for the Black interviewer. For self-perceptions of one's own behavior, the Cronbach $\alpha$ s were .86 for interactions with the White interviewer and .85 for interactions with the Black interviewer. In contrast to the results subsequently reported for evaluative ratings, there were no consistent effects for the potency ratings. Details of these analyses are available from the first author. 


\section{Results}

The analyses first examined response latencies in the priming task, next the relationship between explicit and implicit measures of prejudice and the relationships of these variables to relative evaluations and nonverbal responses to Black and White interviewers, and then how participants perceived their own behavior.

Priming and response latencies. Preliminary analysis demonstrated that the overall error rate was low (2.8\%) and not systematically related to the experimental conditions. The occurrence of outliers was again rare $(2.6 \%)$. For the latency measure, the 2 (Participant Sex) $\times 2$ (Stimulus Order) $\times 2$ (Race of Facial Prime: White and Black) $\times 2$ (Favorability of Target Word: Positive and Negative) analysis of variance, with repeated measures on the last two independent variables revealed a marginally significant Race Prime $\times$ Target Word Favorability interaction, $F(1,29)=3.29, p<.08$. This effect was independent of sex and order; no higher-order interactions were obtained. As predicted and found for the first two studies, response times to negative target words were significantly faster following the Black prime than following the White prime, $M \mathrm{~s}=911 \mathrm{vs} 1020 \mathrm{~ms}$, $t(32)=3.72, p<.001$. As in Experiment 2, however, there was no significant difference for positive words as a function of the racial prime, $p=.20$. In fact, response times were slightly slower following the White primes than following the Black primes, $M \mathrm{~s}=814 \mathrm{vs} 777 \mathrm{~ms}$. Overall, though, the interaction pattern closely replicates the results of Experiment 2, which used the same priming procedure and stimuli.

Prejudice, evaluations and nonverbal behaviors. In this study, the primary response-latency measure of bias was uncorrelated with Modern Racism, $r(31)=$ $.01, p=.98$, and with Old-Fashioned Racism, $r(31)=-.07, p=.71$. The four supplementary measures of response latency bias were also uncorrelated with the explicit measures of prejudice (see Table 1).

It was hypothesized that explicit measures of prejudice would primarily predict relative evaluations of Black and White interviewers, whereas response-latency bias would primarily predict nonverbal behaviors. Zero-order correlations generally supported these predictions. For ratings of the interviewers, the extent to which participants evaluated the White interviewer more favorably than the Black interviewer was positively correlated with both Modern Racism, $r(31)=.54$, $p<.001$, and Old-Fashioned Racism, $r(31)=.37, p<.034$. Participants who scored higher on the Modern and Old-Fashioned Racism scales evaluated the Black interviewer less favorably than the White interviewer. The response-latency measure of bias was not associated with ratings of evaluation, $r(31)=.02$, $p<.93$.

In contrast to the results for ratings of the interviewers and consistent with the predictions, significant correlations were obtained between the nonverbal behaviors and the response-latency measure of bias but not between the nonverbal behaviors and self-report measures of prejudice. For the response-latency measure, higher levels of racial bias were associated with higher rates of blinking with the Black than with the White interviewer, $r(31)=.43, p<.012$, and with less 
visual contact, $r(31)=-.40, p<.022$. Scores on the Modern and Old-Fashioned Racism scales were not related to relative rates of blinking, $r \mathrm{~s}=.07$ and -.04 , $p \mathrm{~s}>.70$, or to visual behavior, $r \mathrm{~s}=.20$ and $.02, p \mathrm{~s}>.25$.

As in Experiment 2, regression equations were also computed in which the dependent variables were, separately, ratings of the interviewers and the two nonverbal behaviors; the independent variables were Old-Fashioned Racism scores, Modern Racism scores, and response-latency bias considered simultaneously. For the equation for bias in evaluative ratings, $F(3,29)=4.06, p<.017$, Modern Racism was the only significant predictor, $\beta=.58, p<.018$. OldFashioned Racism $(\beta=-.05, p<.83)$ and response-latency bias $(\beta=.01$, $p<.95)$ were nonsignificant predictors.

For the equation predicting relative rates of blinking, $F(3,29)=2.39$, $p<.089$, response-latency bias was the only significant predictor, $\beta=.42$, $p<.018$. Modern Racism $(\beta=.16, p<.51)$ and Old-Fashioned Racism $(\beta=-.13, p<.59)$ had nonsignificant relations. In the equation for percent of time with visual contact, $F(3,29)=3.21, p<.038$, response-latency bias was again the only significant predictor, $\beta=-.42, p<.014$. The effect for Old-Fashioned Racism was nonsignificant $(\beta=-.33, p<.17)$, but the effect for Modern Racism unexpectedly approached significance $(\beta=-.45, p<.067)$. Participants higher in Modern Racism tended to have greater visual contact with White than with Black interviewers. Overall, the results are consistent with predictions.

Finally, to compare how participants scoring relatively high or low in explicit and implicit measures of prejudice responded to Black and White interviewers in terms of mean levels of responses to the Black and White interviewers, 2 (High vs Low in Modern Racism, determined by a median split) $\times 2$ (High vs Low in Response Latency Bias, determined by a median split) $\times 2$ (Participant Sex) $\times 2$ (Race of Interviewer) analyses of variance (ANOVA), with repeated measures on the last factor, were performed. It was expected that effects for ratings of the interviewers would primarily be a function of scoring high or low in Modern Racism, ${ }^{3}$ not a function of performance on the response-latency task. In contrast, it was anticipated that effects for the nonverbal behaviors would be related more to performance on the response-latency task than to self-reported prejudice.

The ANOVA on the evaluative scores demonstrated, as expected, a Modern Racism $\times$ Interviewer Race interaction, $F(1,25)=6.99, p<.014$. Low prejudice-scoring participants indicated more favorable evaluations of the Black interviewer than of the White interviewer, $M \mathrm{~s}=5.93$ vs $4.62, t(13)=2.59$, $p<.022$. In contrast, high prejudice-scoring participants evaluated the White interviewer more positively than the Black interviewer, $M \mathrm{~s}=4.79$ vs 5.26 , $t(18)=2.11, p<.049$.

${ }^{3}$ A parallel set of analyses was conducted using the median split on Old-Fashioned Racism scores. The results resembled those obtained for Modern Racism but were much weaker and nonsignificant. 
The analysis for rates of blinking demonstrated, as anticipated, a ResponseLatency Bias $\times$ Interviewer-Race interaction, $F(1,25)=51.88, p<.001$. Participants scoring above the median on the response-latency measure of bias exhibited a significantly higher rate of blinking with the Black interviewer than with the White interviewer, $M \mathrm{~s}=0.44$ vs $0.26, t(16)=2.96, p<.009$. Participants scoring below the median had a somewhat but not significantly lower rate of blinking with the Black relative to the White interviewer, $M \mathrm{~s}=0.25 \mathrm{vs}$ $0.37, t(15)=-1.48, p<.16$. Unexpectedly, a Modern Racism $\times$ Interviewer Race interaction was also obtained, $F(1,25)=29.47, p<.001$. Low prejudicescoring participants showed equivalent rates of blinking with Black and White interviewers, $M \mathrm{~s}=0.35$ vs $0.39, t(13)=-0.40, p<.70$, whereas high prejudice-scoring participants showed a somewhat higher rate of blinking with the Black interviewer than with the White interviewer, $M \mathrm{~s}=0.34$ vs $0.26, t(18)=$ $1.65, p<.12$. As hypothesized, the interaction effect was considerably more pronounced when participants were classified as high or low in prejudice on the response-latency measure than on the Modern Racism scale.

The ANOVA for percent of visual contact revealed a significant ResponseLatency Bias $\times$ Interviewer-Race interaction, $F(1,25)=4.97, p<.035$. Participants scoring above the median on the response-latency measure of bias looked somewhat less at the Black interviewer than at the White interviewer, $M \mathrm{~s}=47.6 \%$ vs $62.7 \%, t(16)=-1.07, p<.31$; in contrast, participants scoring below the median looked more at the Black than the White interviewer, $M \mathrm{~s}=$ $50.3 \%$ vs $40.0 \%, t(15)=2.42, p<.029$. The Modern Racism $\times$ InterviewerRace interaction did not approach significance, $F<1$.

Perceptions of own behavior. Participants were also asked to rate their own behavior toward Black and White interviewers on the evaluative items. Analyses of variance demonstrated that, overall, participants reported behaving equally positively toward the Black and White interviewers, $M \mathrm{~s}=4.89$ vs $4.92, F<1$. Consistent with the expectation that self-reports would predict overt manifestations of bias, Modern Racism scores were positively correlated with ratings of behaving more favorably toward the White interviewer than the Black interviewer, $r(31)=.37, p<.037$; the correlation was also positive but somewhat weaker and nonsignificant for Old-Fashioned Racism scores, $r=.12$. The weakest correlation was, as anticipated, for response latency bias, $r=.07$.

Self-perceptions of behaving positively, however, were not related to differences in the nonverbal behaviors displayed with White and Black interviewers: relative rate of blinking, $r=-.17$; relative time in visual contact, $r=-.03$. Thus, how participants perceived their own behavior was largely independent of the differences in nonverbal behavior that they displayed with Black and White interviewers.

\section{Discussion}

Experiment 3 provides converging evidence to the findings and conclusions of the first two studies. The priming task again revealed evidence of systematic, 
negative implicit attitudes of Whites toward Blacks. The pattern of results closely paralleled those of Experiment 2, which used essentially the same priming procedure. Race Prime $\times$ Target Word Favorability interactions were obtained ( $p<.03$ for Experiment $2 ; p<.08$ for Experiment 3 ), and the effect of the racial primes was more pronounced for negative words than for positive words. A Race Prime $\times$ Trait Favorability $\times$ Study (Experiment 2 vs Experiment 3 ) analysis of variance performed on the transformed response-latency scores revealed a significant Race Prime $\times$ Trait Favorability interaction across the two studies, $F(1,62)=8.14, p<.006$. This effect was comparable across the two experiments; the Study $\times$ Race Prime $\times$ Trait Favorability interaction did not approach significance, $F(1,62)=0.36, p<.550$. Overall, participants responded faster to negative words following a Black prime than following a White prime; the difference was not statistically significant for positive words. These findings provide additional evidence of systematically negative implicit attitudes of Whites toward Blacks.

This study also complements Experiment 2 by offering support for the hypothesis that implicit attitudes would primarily predict more spontaneous race-related behaviors, whereas self-reported racial prejudice would primarily predict more deliberative responses. Experiment 3 involved actual face-to-face interaction and the measures used to represent spontaneous responses (nonverbal behaviors vs word completions) and deliberative response (evaluations vs juridic judgments of guilt) were quite different from those used in Experiment 2. Nevertheless, like those of Experiment 2, the data from Experiment 3 support these hypotheses.

We acknowledge, however, that a definitive taxonomy of spontaneous and deliberative behavior does not exist and that a comparison across different types of responses can involve variations along multiple dimensions. The parallel results we observed for very different operationalizations of these concepts across Experiments 2 and 3 lend support to our framework, but future studies might attempt to use the same dependent measures while manipulating circumstances that would permit or promote deliberative responding to varying degrees. Previous research supporting the MODE Model (e.g., Sanbonmatsu \& Fazio, 1990) has examined the effects of manipulations of motivation and opportunity for deliberation on subsequent heuristic and deliberative decision-making. Future research on race-related decisions could similarly manipulate motivation by varying the degree to which participants' responses would be public or anonymous (Crosby et al., 1980) and opportunity by varying time pressure for making the decision. Alternatively, the research on subtle forms of racism may provide paradigms for examining the differential validity of implicit and explicit attitudes. Research supporting the aversive racism framework, for example, has found that discrimination against Blacks by Whites is unlikely to occur when norms for appropriate behavior are clear but often does occur when Whites can justify or rationalize a negative response on the basis of some factor other than race (e.g., by diffusing responsibility; Gaertner \& Dovidio, 1977). Whereas explicit attitudes may predict 
Whites' responses in the former case, implicit attitudes may predict discrimination in the latter case. In general, then, our experiment not only provides evidence that response-latency measures can systematically predict subsequent race-related responses but also suggests when these effects occur.

We also note that because some behaviors are more spontaneous, that does not mean that they are necessarily less consequential in their effects than are more deliberative behaviors. Nonverbal behaviors, for instance, can have a profound impact on people's perceptions of and reactions to others (DePaulo \& Friedman, 1997). In addition to communicating attraction and attitude, nonverbal behaviors can shape the nature of interactions, subtly influencing outcomes in systematic ways. Word, Zanna, and Cooper (1974) demonstrated the potential adverse impact of nonverbally mediated expectancy effects in interracial interactions. They found that White interviewers behaved less positively nonverbally with Blacks than with Whites. Furthermore, interviewers who were trained to exhibit these less positive nonverbal displays produced inferior applicant performance among naive White interviewees than did interviewers trained with the more favorable displays associated with Whites. Outside the laboratory, nonverbal communication of warmth is a key factor communicating teachers' expectations of students (Harris \& Rosenthal, 1985). These nonverbal cues can be detected from very short (e.g., 30-s) segments of behavior (Ambady \& Rosenthal, 1993). Thus, although bias may be unconscious and transmitted in subtle ways, its impact can be quite significant.

The effects of this subtle transmission of bias may also be quite insidious and contribute to distrust and suspicion between Blacks and Whites. Participants in Experiment 3 reported that they acted in an equally likable and sincere manner with Black and White partners, but their nonverbal behaviors were inconsistent with their perceptions-and perhaps with their intentions. As suggested by the aversive racism framework, racial bias may be manifested outside of one's awareness. Thus, in interracial interaction Whites may intend to convey a positive and friendly attitude toward their Black partner and believe that they have succeeded. In assessing the behavior of the White person, however, Blacks may not only consider the overt, consciously controlled behavior of the partner, but also concentrate on the less conscious behaviors (such as eye contact and nonverbal expression of discomfort) that Whites may have difficulty monitoring and controlling. Thus, while the White person may feel that he or she is acting in a personable and accepting manner, in the same interaction the Black partner may be attuned to the negative or mixed-message inadvertently sent (see Devine, Evett, \& Vasquez-Suson, 1996), which produces a very different, potentially conflicting, perspective that can contribute to racial tension and distrust. This line of reasoning is consistent with the finding of Fazio et al. (1995) that a Black experimenter's perceptions of White participants' friendliness was better predicted by their implicit attitudes than by their explicit attitudes. 


\section{GENERAL DISCUSSION}

A meta-analysis across the three experiments reveals clear evidence of a negative response-latency bias among participants. Overall, across the three studies, response-latency bias corresponding to the Race $\times$ Target Word Favorability interaction (i.e., the extent to which participants responded more slowly to positive words and more quickly to negative words following a Black prime than following a White prime) was statistically reliable, mean $r=.447, z=4.18, p<$ .001 , fail-safe number $=18$. Corresponding to the simple effects tests, the meta-analytic effect of Prime was significant for negative target words, mean $r=$ $.593, z=5.97, p<.001$ (one-tailed), but was only marginally significant for positive words, mean $r=.176, z=1.54, p=.062$ (one-tailed). These findings further demonstrate the existence of implicit attitudes in general (Greenwald \& Banaji, 1995), support Wegner and Bargh's (1997) conclusion that "the automatic activation of evaluations or attitudes by the mere presence of the attitude object in the environment is a ubiquitous phenomenon" (p. 25), and converge with studies showing systematic implicit racial biases among Whites (Devine, 1989; Dovidio \& Gaertner, 1993; Fazio et al., 1995; Judd et al., 1995; Lepore \& Brown, 1997).

Furthermore, in the present research, this effect was obtained despite the fact that these same participants scored very low on self-report measures of the traditional form of prejudice represented by Old-Fashioned Racism (Experiment 2: $M=1.55$; Experiment 3: $M=1.28$, on a $1-5$ scale) and low on a measure intended to assess a more contemporary and subtle form of bias, Modern Racism (Experiment 1, $M=1.57$; Experiment 2: $M=1.85$; Experiment 3: $M=1.67$, also on a 1-5 scale; see also Fazio et al., 1995). Whereas the aversive racism framework (Dovidio \& Gaertner, 1997; Gaertner \& Dovidio, 1986) has presented it as a theoretical assumption rather than an empirical demonstration, this pattern offers direct evidence that many Whites who report being nonprejudiced on traditional measures of prejudice do indeed harbor unconscious negative attitudes toward Blacks.

The present research, however, also further calls into question whether the Modern Racism Scale is a nonreactive measure of racial prejudice (McConahay, 1986, p. 577). One criticism has been that the scale confounds political conservatism with prejudice (Sniderman \& Tetlock, 1986a, 1986b). What the present research also suggests is that it may now be closely aligned with traditional racism. Although scores on the Modern Racism Scale were generally higher than those on the Old-Fashioned Racism Scale, scores on the Modern Racism Scale were highly correlated with measures of more traditional forms of racism across the three studies. As a consequence of the closer alignment with traditional racism, Modern Racism may no longer represent a subtle manifestation of personal attitudes but may be a public expression that is shaped significantly by social desirability concerns (see also Fazio et al., 1995). As McConahay (1986) anticipated, "new items will have to be generated for the Modern Racism Scale as new issues emerge in American race relations and some of the current scale items become more reactive" (p. 123). This may help explain why the results for 
Modern Racism and measures of traditional racism were generally similar across our three experiments.

The reactivity of the Modern Racism Scale and particularly the Old-Fashioned Racism Scale might also help to account for the quite variable set of correlations between self-report measures of prejudice and the response-latency measure of bias across our three experiments. In Experiment 1, the combined measure of response-latency bias (i.e., the extent to which participants responded more slowly to positive words and more quickly to negative words following a Black prime than a White prime) correlated somewhat but not significantly positively with Modern Racism $(r=.15)$ and Attitudes Toward Blacks Modern Racism $(r=.28)$; in Experiment 2 significant positive relationships were found between the response-latency measure and Modern Racism $(r=.60)$ and Old-Fashioned Racism ( $r=.49)$; in Experiment 3, the comparable correlations were again weak and nonsignificant $(r \mathrm{~s}=.01$ and -.07$)$. The significant positive correlations between implicit and explicit attitudes were obtained when the level of racial bias expressed on the self-report scales was highest (Modern Racism mean for Experiment $2=1.85$, for Experiment $3=1.67$, for Experiment $1=1.57$ [on a 5-item scale]). Old-Fashioned Racism scores were significantly higher $(p<.04)$ in Experiment 2 than in Experiment 3. (The Old-Fashioned Racism Scale was not used in Experiment 1.)

It is possible that, with experience at college, students become increasingly aware of norms of being nonprejudiced and perhaps come to internalize these norms, producing lower levels of self-reported racial prejudice. Consistent with this reasoning, participants in Experiment 3 who displayed very low levels of Old-Fashioned Racism were advanced undergraduates who volunteered to participate. Participants in Experiments 1 and 2 were primarily first-year students. Jackman and Muha (1984) argue that better educated people are the most sophisticated practitioners of racial bias. This reasoning suggests that correlations between implicit and explicit racial attitudes would be stronger for subgroups whose norms are more permissive of the overt expression of bias. The relationship would be weaker for people who adhere more to nonprejudiced norms. This represents one potential avenue for future research to consider.

The fact that negative attitudes may exist and be expressed automatically does not mean that racial bias is inevitable or immutable and may, in fact, suggest ways of producing truly nonprejudiced attitudes-implicitly as well as explicitly. The work of Devine (1989; Monteith \& Devine, 1993) suggests that implicit prejudice is like a "bad habit." It is an overlearned response that can be unlearned. An important first step is making people aware of discrepancies between their conscious ideals and automatic negative responses. By making these nonconscious negative responses conscious, it may be possible to take advantage of the genuinely good intentions of aversive racists to motivate them to gain the experiences they need to unlearn one set of responses and learn the new set that they desire.

Research by Devine and Monteith (1993) illustrates how awareness of inconsis- 
tency between one's interracial behavior and one's egalitarian standards produces a negative emotional reaction and a genuine motivation to behave in a more egalitarian fashion in the future. Specifically, they found that people who indicated that they were relatively nonprejudiced exhibited feelings of guilt and compunction when they became aware of discrepancies between their potential behavior toward minorities (i.e., what they would do) and their personal standards (i.e., what they should do). These emotional reactions, in turn, can motivate people to control subsequent spontaneous stereotypical responses and behave more favorably in the future (Monteith, 1993). Recently, Blair and Banaji (1996) demonstrated that conscious efforts to suppress stereotypically biased reactions can inhibit even the immediate activation of normally automatic associations. Although implicit negative racial attitudes among Whites may be generally unconscious and automatic, these responses are not inevitable.

The present study also raises important questions for future research. More work is needed on the measurement characteristics (e.g., reliability, convergent validity) of priming techniques and other measures of implicit attitudes. If response-latency techniques are to be used as individual-difference measures for predicting future behavior, their psychometric properties need to be more firmly understood and established. Understanding these properties may help to account for the highly variable correlations between implicit and explicit measures of attitudes across the present three studies and other research (e.g., Fazio et al., 1995). With respect to behavior, the spontaneous-deliberative distinction requires further conceptual refinement that identifies the factors (e.g., cognitive effort, evaluative concerns) that critically define behaviors as deliberative. Nevertheless, the present study continues to suggest the importance of recognizing the subtlety and complexity of Whites' contemporary racial attitudes and of appreciating how these attitudes combine to shape the interracial behaviors of Whites toward Blacks and the reciprocal actions of Blacks toward Whites.

\section{REFERENCES}

Ambady, N., \& Rosenthal, R. (1993). Half a minute: Predicting teacher evaluations from thin slices of nonverbal behavior and physical attractiveness. Journal of Personality and Social Psychology, 64, 431-441.

Baker, S. M., \& Devine, P. G. (1988, April). Faces as primes for stereotype activation. Paper presented at the 60th annual meeting of the Midwestern Psychological Association, Chicago.

Banaji, M. R., \& Greenwald, A. G. (1995). Implicit gender stereotyping in judgments of fame. Journal of Personality and Social Psychology, 68, 181-198.

Banaji, M. R., \& Greenwald, A. G. (1994). Implicit stereotyping and prejudice. In M. P. Zanna and J. M. Olson (Eds.), The psychology of prejudice: The Ontario symposium (Vol. 7, pp. 55-76). Hillsdale, NJ: Erlbaum.

Banaji, M. R., \& Hardin, C. D. (1996). Automatic gender stereotyping. Psychological Science, 7, $136-141$.

Bargh, J. A. (1994). The Four Horsemen of automaticity: Awareness, intention, efficiency, and control in social cognition. In R. S. Wyer \& T. K. Srull (Eds.), Handbook of social cognition (2nd ed., Vol. 1, pp. 1-40). Hillsdale, NJ: Erlbaum.

Bargh, J. A., \& Chen, M. (1996). The chameleon effect: Automatic social perception produces automatic social behavior. Manuscript submitted for publication. 
Bargh, J. A., \& Pietromonaco, P. (1982). Automatic information processing and social perception: The influence of trait information presented outside of awareness on impression formation. Journal of Personality and Social Psychology, 43, 437-449.

Blair, I., \& Banaji, M. R. (1996). Automatic and controlled processes in gender stereotyping. Journal of Personality and Social Psychology, 70, 1142-1163.

Bodenhausen, G. V., \& Lichtenstein, M. (1987). Social stereotypes and information processing strategies: The impact of task complexity. Journal of Personality and Social Psychology, 52, 871-888.

Brigham, J. C. (1971). Racial stereotypes, attitudes, and evaluations of and behavioral intentions toward Negroes and Whites. Sociometry, 34, 360-380.

Brigham, J. C. (1993). College students' racial attitudes. Journal of Applied Social Psychology, 23, 1933-1967.

Costanzo, S., \& Costanzo, M. (1994). Life and death decisions: An analysis of capital jury decision-making under the special issues sentencing framework. Law and Human Behavior, 18, 151-170.

Crosby, F., Bromley, S., \& Saxe, L. (1980). Recent unobtrusive studies of black and white discrimination and prejudice: A literature review. Psychological Bulletin, 87, 546-563.

DePaulo, B. M. (1992). Nonverbal behavior and self-presentation. Psychological Bulletin, 111, 203-243.

DePaulo, B. M., \& Friedman, H. S. (1997). Nonverbal communication. In D. T. Gilbert, S. T. Fiske, \& G. Lindzey (Eds.), The handbook of social psychology (4th Ed.). New York: McGraw-Hill.

Devine, P. G. (1989). Stereotypes and prejudice: The automatic and controlled components. Journal of Personality and Social Psychology, 56, 5-18.

Devine, P. G., Evett, S. R., \& Vasquez-Suson, K. A. (1996). Exploring the interpersonal dynamics of intergroup contact. In R. M. Sorrentino \& E. T. Higgins (Eds.), Handbook of motivation and cognition (Vol. 3 pp. 423-464). New York: Guilford.

Devine, P. G., \& Monteith, M. J. (1993). The role of discrepancy-associated affect in prejudice reduction. In D. M. Mackie \& D. L. Hamilton (Eds.), Affect, cognition, and stereotyping: Interactive processes in intergroup perception (pp. 317-344). Orlando, FL: Academic Press.

Doering, D. G. (1957). The relation between manifest anxiety and rate of eyeblink in stress situations. (Report No. 6, Project No. NM130199). San Antonio, TX: U.S. Air Force School of Aviation Medicine, Brooks Air Force Base.

Dovidio, J. F., Brigham, J. C., Johnson, B. T., \& Gaertner, S. L. (1996). Stereotyping, prejudice, and discrimination: Another look. In N. Macrae, C. Stangor, \& M. Hewstone (Eds.), Foundations of stereotypes and stereotyping (pp. 276-319). New York: Guilford.

Dovidio, J. F., Brown, C. E., Heltman, K., Ellyson, S. L., \& Keating, C. F. (1988). Power displays between women and men in discussions of gender-linked tasks: A multichannel study. Journal of Personality and Social Psychology, 55, 580-587.

Dovidio, J. F., \& Ellyson, S. L. (1985). Patterns of visual dominance behavior in humans. In S. L. Ellyson \& J. F. Dovidio (Eds.), Power, dominance, and nonverbal behavior (pp. 129-149). New York: Springer-Verlag.

Dovidio, J. F., Evans, N., \& Tyler, R. B. (1986). Racial stereotypes: The contents of their cognitive representations. Journal of Experimental Social Psychology, 22, 22-37.

Dovidio, J. F., \& Fazio, R. H. (1992). New technologies for the direct and indirect assessment of attitudes. In J. Tanur (Ed.), Questions about survey questions: Meaning, memory, attitudes, and social interaction (pp. 204-237). New York: Russell Sage Foundation.

Dovidio, J. F., \& Gaertner, S. L. (1991). Changes in the nature and expression of racial prejudice. In H. Knopke, J. Norrell, \& R. Rogers (Eds.), Opening doors: An appraisal of race relations in contemporary America (pp. 201-241). Tuscaloosa, AL: Univ. of Alabama Press.

Dovidio, J. F., \& Gaertner, S. L. (1993). Stereotypes and evaluative intergroup bias. In D. M. Mackie \& D. L. Hamilton (Eds.), Affect, cognition, and stereotyping (pp. 167-193). San Diego: Academic Press. 
Dovidio, J. F., \& Gaertner, S. L. (1997). On the nature of contemporary prejudice: The causes, consequences, and challenges of aversive racism. In J. Eberhardt \& S. T. Fiske (Eds.), Racism: The problem and the response. Newbury Park, CA: Sage.

Dovidio, J. F., Mann, J. A., \& Gaertner, S. L. (1989). Resistance to affirmative action: The implication of aversive racism. In F. A. Blanchard \& F. J. Crosby (Eds.). Affirmative action in perspective (pp. 83-102). New York: Springer-Verlag.

Eagly, A. H., \& Kite, M. E. (1987). Are stereotypes of nationalities applied to both women and men? Journal of Personality and Social Psychology, 53, 451-462.

Efran, J. S. (1968). Looking for approval: Effects of visual behavior of approbation from persons differing in importance. Journal of Personality and Social Psychology, 10, 21-25.

Efran, J. S., \& Broughton, A. (1966). Effects of expectancies for social approval on visual behavior. Journal of Personality and Social Psychology, 4, 103-107.

Ellyson, S. L., \& Dovidio, J. F. (Eds.) (1985). Power, dominance, and nonverbal behavior. New York: Springer-Verlag.

Exline, R. V. (1972). Visual interaction: The glances of power and preference. In J. K. Cole (Ed.), The Nebraska symposium on motivation, 1971 (pp. 163-208, Vol. 19). Lincoln, NE: Univ. of Nebraska Press.

Exline, R. V. (1985). Multichannel transmission of nonverbal behavior and the perception of powerful men: The presidential debates of 1976. In S. L. Ellyson \& J. F. Dovidio (Eds.), Power, dominance, and nonverbal behavior (pp. 183-206). New York: Springer-Verlag.

Faranda, J., \& Gaertner, S. L. (1979, March). The effects of inadmissible evidence introduced by the prosecution and the defense, and the defendant's race on the verdicts by high and low authoritarians. Paper presented at the annual meeting of the Eastern Psychological Association, New York.

Fazio, R. H. (1987). Self-perception theory: A current perspective. In M. P. Zanna, J. M. Olson, \& C. P. Herman (Eds.), Social influence: The Ontario symposium (Vol. 5, pp. 129-150). Hillsdale, NJ: Erlbaum.

Fazio, R. H. (1990). Multiple processes by which attitudes guide behavior: The MODE model as an integrative framework. In M. P. Zanna (Ed.), Advances in experimental social psychology (Vol. 23, pp. 75-109). Orlando, FL: Academic Press.

Fazio, R. H., Jackson, J. R., Dunton, B. C., \& Williams, C. J. (1995). Variability in automatic activation as an unobtrusive measure of racial attitudes: A bona fide pipeline? Journal of Personality and Social Psychology, 69, 1013-1027.

Fazio, R. H., \& Zanna, M. P. (1981). Direct experience and attitude-behavior consistency. In L. Berkowitz (Ed.), Advances in experimental social psychology (Vol. 14, pp. 162-202). New York: Academic Press.

Fugita, S. S. (1974). Effects of anxiety and approval on visual interaction. Journal of Personality and Social Psychology, 29, 586-592.

Gaertner, S. L., \& Dovidio, J. F. (1977). The subtlety of white racism, arousal, and helping behavior. Journal of Personality and Social Psychology, 35, 691-707.

Gaertner, S. L., \& Dovidio, J. F. (1986). The aversive form of racism. In J. F. Dovidio \& S. L. Gaertner (Eds.), Prejudice, discrimination, and racism (pp. 61-89). Orlando, FL: Academic Press.

Gaertner, S. L., \& McLaughlin, J. P. (1983). Racial stereotypes: Associations and ascriptions of positive and negative characteristics. Social Psychology Quarterly, 46, 23-30.

Gilbert, D. T., \& Hixon, J. G. (1991). The trouble of thinking: Activation and application to stereotypic beliefs. Journal of Personality and Social Psychology, 60, 509-517.

Greenwald, A. G., \& Banaji, M. R. (1995). Implicit social cognition: Attitudes, self-esteem, and stereotypes. Psychological Review, 102, 4-27.

Greenwald, A. G., Klinger, M. R., \& Liu, T. J. (1989). Unconscious processing of dichoptically masked words. Memory and Cognition, 17, 35-47.

Harris, M. J., \& Rosenthal, R. (1985). Mediation of interpersonal expectancy effects: 31 metaanalyses. Psychological Bulletin, 97, 363-386. 
Harper, R. G. (1985). Power, dominance, and nonverbal behavior: An overview. In S. L. Ellyson \& J. F. Dovidio (Eds.), Power, dominance, and nonverbal behavior (pp. 29-48). New York: Springer-Verlag.

Jackman, M. R., \& Muha, M. J. (1984). Education and intergroup attitudes: Moral enlightenment, superficial democratic commitment, or ideological refinement? American Sociological Review, 49, 751-769.

Johnson, S. L. (1985). Black innocence and the white jury. Michigan Law Review, 83, 1611-1708.

Judd, C. M., Park, B., Ryan, C. S., Brauer, M., \& Kraus, S. (1995). Stereotypes and ethnocentrism: Diverging interethnic perceptions of African American and White American Youth. Journal of Personality and Social Psychology, 69, 460-481.

Kanfer, F. H. (1960). Verbal rate, eyeblink, and content in structured psychiatric interviews. Journal of Abnormal and Social Psychology, 61, 341-347.

Kleinke, C. L. (1986). Gaze and eye contact: A research review. Psychological Bulletin, 100, 78-100.

Kleinke, C. L., Meeker, F. B., \& LaFong, C. (1974). Effects of gaze, touch, and use of name on evaluation of "engaged" couples. Journal of Research in Personality, 7, 368-373.

Kovel, J. (1970). White racism: A psychohistory. New York: Pantheon.

Lepore, L., \& Brown, R. (1997). Category and stereotype activation: Is prejudice inevitable? Journal of Personality and Social Psychology, 72, 275-287.

Loftus, E. F., \& Klinger, M. R. (1992). Is the unconscious smart or dumb? American Psychologist, 47, 761-765.

McConahay, J. B. (1986). Modern racism, ambivalence, and the modern racism scale. In J. F. Dovidio \& S. L. Gaertner (Eds.), Prejudice, discrimination, and racism (pp. 91-125). Orlando, FL: Academic Press.

McConahay, J. B., Hardee, B. B., \& Batts, V. (1981). Has racism declined in America? It depends upon who is asking and what is asked. Journal of Conflict Resolution, 25, 563-579.

Monteith, M. (1993). Self-regulation of prejudiced responses: Implications for progress in prejudicereduction efforts. Journal of Personality and Social Psychology, 65, 469-485.

Neely, J. (1977). Semantic priming and retrieval from lexical memory: Roles of inhibitionless spreading activation and limited-capacity attention. Journal of Experimental Psychology: General, 106, 226-254.

Neely, J. (1991). Semantic priming effects in visual word recognition: A selective review of current findings and theories. In D. Besner \& G. Humphreys (Eds.), Basic processes in reading: Visual word recognition (pp. 264-336). Hillsdale, NJ: Erlbaum.

Perdue, C. W., Dovidio, J. F., Gurtman, M. B., \& Tyler, R. B. (1990). "Us" and "Them": Social categorization and the process of intergroup bias. Journal of Personality and Social Psychology, 59, 475-486.

Posner, M. I., \& Snyder, C. R. (1975). Attention and cognitive control. In R. L. Solso (Ed.), Information processing and cognition: The Loyola symposium (pp. 55-85). Hillsdale, NJ: Erlbaum.

Ratcliff, R. (1993). Methods for dealing with reaction time outliers. Psychological Bulletin, 114, 510-532.

Roese, N. J., \& Jamieson, D. W. (1993). Twenty years of bogus pipeline research: A critical review and meta-analysis. Psychological Bulletin, 114, 363-375.

Rubin, Z. (1970). Measurement of romantic love. Journal of Personality and Social Psychology, 16, 265-273.

Sanbonmatsu, D. M. \& Fazio, R. H. (1990). The role of attitudes in memory-based decision making. Journal of Personality and Social Psychology, 59, 614-622.

Schacter, D. L. (1990). Introduction to "Implicit memory: Multiple perspectives." Bulletin of the Psychonomic Society, 28(4), 338-340.

Sears, D. O. (1988). Symbolic racism. In P. A. Katz \& D. A. Taylor (Eds.), Eliminating racism: Profiles in controversy (pp. 53-84). New York: Plenum.

Sigall, H., \& Page, R. (1971). Current stereotypes: A little fading, a little faking. Journal of Personality and Social Psychology, 18, 247-255. 
Sniderman, P. M., \& Tetlock, P. E. (1986a). Symbolic racism: Problems of motive attribution in political analysis. Journal of Social Issues, 42, 129-150.

Sniderman, P. M., \& Tetlock, P. E. (1986b). Reflections on American racism. Journal of Social Issues, 42, 173-187.

Wegner, D. M., \& Bargh, J. A. (1997). Control and automaticity in social life. In D. T. Gilbert, S. T. Fiske, \& G. Lindzey (Eds.), The Handbook of Social Psychology (4th Ed.). New York: McGraw-Hill.

Williams, J. E., Tucker, R. D., \& Dunham, F. Y. (1971). Changes in the connotations of color names among Negroes and Caucasians. Journal of Personality and Social Psychology, 19, 222-228.

Word, C. O., Zanna, M. P., \& Cooper, J. (1974). The nonverbal mediation of self-fulfilling prophecies in interracial interaction. Journal of Experimental Social Psychology, 10, 109-120.

Zanna, M. P., \& Fazio, R. H. (1982). The attitude-behavior relation: Moving toward a third generation of research. In M. P. Zanna, E. T. Higgins, \& C. P. Herman (Eds.), Consistency in social behavior: The Ontario symposium (Vol. 2, pp. 283-301). Hillsdale, NJ: Erlbaum. 